\title{
Teacher training: a model for introducing innovative digital methodologies for learning Mathematics
}

\author{
Barana, Alice $^{a}$; Fioravera, Michele ${ }^{a}$ and Marchisio, Marina ${ }^{a}$ \\ ${ }^{a}$ Department of Mathematics, University of Turin, Italy.
}

\begin{abstract}
This paper shows a model of teacher training developed by the Department of Mathematics of the University of Turin, aimed at introducing teachers to the use of innovative methodologies for learning Mathematics and for developing disciplinary and cross-cutting competences. The learning methodologies proposed are mainly based on Problem Posing and Problem Solving, the use of an Advanced Computing Environment, of a Virtual Learning Environment and of an Automated Assessment System. The training model, designed in blended modality, mainly relies on the creation of an online community of practice, where teachers, supported by tutors, collaborate in the creation of interactive learning materials for their classes. They acquire competences not only in the use of learning technologies, but also on sharing and collaborating in virtual environments; they learn how to develop self-tailored didactic methodologies. The key strengths of this model are highlighted and the results, achieved after the experimentation in several projects, are discussed, showing the effectiveness of the model.
\end{abstract}

Keywords: Advanced Computing Environment; Automatic Assessment System; Mathematics; Problem Posing and Solving; Teacher training; Virtual Learning Environment. 


\section{Introduction}

Mathematics education is at the core of recent international discussions (PISA, 2003), which have been followed by the definition of new European aims and directions (Council of European Union, 2009) (Official Journal of the European Union, 2006), in turn followed by national guidelines and reforms (MIUR, 2010) (MIUR, 2015). They all clearly express the necessity to address teaching towards a competence-based approach to develop problem solving competences, supported by the use of technologies. Since every reform on teaching cannot actually be realized without a spread and rooted awareness that changes are needed, governments had to make a great effort in teacher training. Many teachers feel the necessity to innovate their methods to meet the interests and expectations of the students of the third millennium (Prensky, 2001), as they realize that old-fashioned methodologies do not work anymore. As students are required to develop disciplinary and cross-cutting competences, so teachers need to develop methodological competencies to design instructional strategies to enhance learning. They need a skilled support to undertake such changes.

In 2012 the University of Turin has been called by the Italian Ministry of Education to support a strong action aimed at innovating Mathematics teaching and learning in the secondary schools (Brancaccio, et al., 2015a). The methodologies proposed, rooted in problem posing and solving, make use of an Advance Computing Environment, a Virtual Learning Environment and an Automatic Assessment System for learning Mathematics. Through this and further experiences, the Department of Mathematics of the University of Turin has developed and experimented a model for teacher training aimed at providing teachers with support, instruments and methodologies for developing - autonomously and collaboratively - instructional practices intended to empower Mathematics learning. This paper shows the methodologies proposed and focuses on the teacher training model developed, presenting and discussing some experiences where it has been applied and the results obtained.

\section{State of the art}

Literature overflows with analysis of teacher training strategies (Avalos, 2011). Different techniques have been proved to be successful to improve teaching skills and students' results: coaching, metacognitive reflection, team working, co-working and many others. Remarkable results have been obtained with the participation to communities of practice (Vescio, et al., 2008), especially when they are focused on the discussion more than on instructional techniques (Supovitz, 2002). The web facilitates the creation and the activity of a community of practice (Ellerani, 2010), especially when participants come from different places. Although, just as different teaching strategies achieve different results depending on the type of students and classes, also training courses should be adjusted 
according to teachers' characteristics and needs (Darling-Hammond \& Bransford, 2007). The model of teacher training shown in this paper is deeply based on an online community of practice, where cooperative learning, course-crossing, synchronous and asynchronous tutoring are fostered.

\section{Innovative digital methodologies for learning Mathematics}

The methodologies proposed for enhancing Mathematics education are the following:

- Problem Posing \& Solving (PP\&S): it promotes the cognitive processes underlying the assessment of students. The main features of the PP\&S consist in the attention that is given to the chosen problematic situations (posing) and the modality in which new technologies are used to find solutions (solving). The student, freed from the burdens of calculations, focuses on solution strategies. The problem posing and problem solving skills developed are also very useful in all disciplines as well as for the formation of a more informed citizen (Brancaccio, et al., 2015a).

- Use of a Virtual Learning Environment (VLE): it opens up a great variety of interaction channels among mentors and learners of different level. The web pages can be realized in different styles, shapes and formats according to the teaching method adopted. VLE structure and tools promote collaboration and sharing ideas and allow the birth of communities of practice. (Lave, 1991).

- Use of an Advanced Computing Environment (ACE): while maintaining the ease and immediacy of use of a common word processor, an ACE enables its users to improve the ability of representing scientific objects. Students' reasoning benefits from numeric computations, symbolic calculus, geometric visualizations in two and three dimensions, and embedding of interactive components where the change of parameters allows to analyze different results (Palumbo \& Zich, 2012).

- Use of an Automated Assessment System (AAS): it has evident advantages for teachers, who have the chance to optimize the development of formative assignments while reducing time-consumption for corrections, and for students, who can practice at their own pace obtaining immediate feedback and results to acknowledge their level of preparation. Both questions and assignments created through the AAS proposed are algorithmically based: students can obtain different data or graphics at every new attempt, guided resolutions, feedback and questions can be automatically proposed on the base of previous answers (Barana \& Marchisio, 2016).

In the projects for teacher training proposed by the Department of Mathematics, instances of the e-learning platform of the University of Turin, maintained by the ICT services from the Department of Computer Science, are used. The platform is integrated with the ACE 
and the AAS, so that teachers and students can benefit from all these advanced tools in the same learning environment.

\section{The model for teacher training}

\subsection{Aims of the model}

The model is intended to provide secondary school teachers with competences on these innovative methodologies for learning Mathematics. In particular, teachers develop skills in problem posing and solving and in the use of a VLE, an ACE and an AAS for learning; they learn how to collaborate online and work in a community, so that they can lead their classes in the development of Mathematics competences.

\subsection{Description of the model}

The teacher training model includes the following features:

1. training modules in presence for a total duration of about 10 hours, organized in:
a. use of an ACE for interactive learning (3 hours),
b. use of an AAS for the formative and summative assessment ( 3 hours),
c. use of a VLE for building learning communities (2 hours),
d. Problem Posing and Problem Solving using an ACE (2 hours);

2. synchronous and asynchronous online training in a VLE, through:

a. forums of discussion for the asynchronous tutoring, monitored by tutors, which foster teachers' collaboration and exchange of materials and experiences,

b. weekly online synchronous tutoring held via a web conference tool integrated in the platform, which allows interactions between tutor and participants through the voice, a chat and the screen-sharing,

c. multimedial didactic materials,

d. databases for sharing didactic materials created and used by teachers;

3. implementation of an online community of practice, which learns and works collaboratively, focused on the enhancement of teaching and learning;

4. tpractice of course-crossing;

5. preparation of materials autonomously and collaboratively and testing on students;

6. evaluation of appreciation and usefulness of the training, for both teachers and students. 


\subsection{Implementation of the model}

Although most of the training takes place online, initial meetings in presence are often recommended, as the face-to-face approach is closer to the teachers' customs. Trainers are university teachers and $\mathrm{PhD}$ students (the latter will become the tutors for the online course) who show the methodologies and help teachers develop their own strategies. The training starts with a change of roles: teachers are asked to be students and to solve a problem, to answer an online assignment or to use the platform from the student's point of view. These activities are useful for introducing teachers to a student-centered approach: after experiencing the students' difficulties, they are keener to understand how they feel after a failure. The training in presence involves activities and tasks for teachers, they immediately start working and creating didactic materials which can be used in their classes. Trainers propose guided examples carefully conceived to be useful for learning how to use the instruments and for creating materials according to the methodologies proposed.

The training continues online in the same VLE that teachers will use with their classes. Once again, they become students and they can avail themselves of the synchronous and asynchronous online resources arranged by the trainers: they get ideas for learning activities to create and experience the effectiveness of these interactive methodologies, so they can be motivated to adopt them in their teaching. Tutors have the fundamental role of connectors between the teachers and the university professors who have designed theses methodologies: their young age (around 25) facilitates teachers to ask questions when in doubt - they are in some cases similar to their children and don't have the austerity of university teachers - so they are considered as a precious support. The training is entirely focused on the methodological use of these learning systems: the disciplinary content is left to the teachers' competence. In such a way, they feel valued and the risk of demotivation is reduced: the effort asked to innovate their teaching involves only the methodology and not the content. In the platform, a community of practice soon comes to life. Sharing (materials, activities, experiences, mistakes, problems, solutions) is fostered not only among teachers, but also between them and tutors. This provides trainers with feedback about teachers' needs and difficulties, precious to improve the training materials, activities and strategies. Collaborative learning can also inspire them to promote collaboration among their students (Barana, et al., 2015). On the platform, teachers' courses are set to allow the coursecrossing: they can enroll to their colleagues' courses without interfering with the gradebook and the tracking of students' activities and with no possibility of editing the course. Feedback, criticism and new ideas thus emerge, promoting teachers' professional and methodological growth.

The entire training is monitored through questionnaires periodically distributed online in order to register both teachers and students' satisfaction, improvements and problems. At 
the end of the training courses teachers receive a certification of achieved competences recognized for their career, which acts as an incentive to participate; anyway, when they start to apply the methodologies developed in their classes, the motivational lever to continue the training is replaced by students' appreciation and results.

\section{Realized experiences, results and discussion}

The model was developed at the Department of Mathematics in 2011, and then used to support the action of the Italian Ministry of Education within the Project Problem Posing and Solving (PP\&S) (Brancaccio, et al., 2015a). Since 2012 about 2400 Italian teachers have been trained on these methodologies. After the training in presence, they have the chance to join the project and continue the training online. The national community of teachers of the PP\&S is still working and is progressively growing: nowadays it counts 1200 teachers from 900 different schools. The initial training in presence received a large appreciation: from questionnaires distributed the overall appreciation reaches 4.1 points in a Likert scale from 1 to 5 (standard deviation: 0.8 ). $97 \%$ of the feedback is positive and $85 \%$ is good or very good. Regarding the online activities, in a survey distributed two years after the beginning of the project the online training was evaluated with 4.0 points on average (st. dev.: 1.0); about $85 \%$ of teachers actively participates to the community, visits other courses and uses the material produced by others. The speed in getting an answer to a request is rated with an average 4.2 (st. dev.: 0.8) and the professionality of tutors with 4.4 (st. dev.: 0.8). The last result supports the assertion that the role of the tutors is strategic in an online community.

On the base of the great success of PP\&S, other projects have been realized in local contexts. For their reduced dimension, they have been monitored more easily; for instance, the project "Lagrange e Cicerone al Computer" involved 35 teachers of high schools of Turin and registered a remarkable success. Results on the appreciation of the training are similar or even higher than those of PP\&S; at the end of the project, teachers felt professionally enriched in a measure of 4.4 out of 5 . In addition, the perception of usefulness of the methodologies proposed in relation with students' results visibly increased just after 8 months, as shown in Figure 1. That means that, in a short time, the training activities proposed made teachers able to change their instructional practices and to verify their effectiveness on students learning.

The flexibility of the model has been tested in projects with different targets, such as the training of university tutors aimed at helping reduce failure of students with difficulties in Mathematics. The training model needed some little adjustments to adapt to the context of remedial education and to university students, mainly involving the material proposed and the level of technical complexity of the use of the systems (Marchisio, et al., 2013). The 
modular schedule allowed to propose a reduced training in the project Digital Mate Training (DMT) only focused on the use of an ACE for problem solving. The training has also been experimented in the Erasmus+ project aimed at discussing the methodologies proposed in the PP\&S in a European scenery. Due to geographical reasons, the training has been conducted only in the online modality, with synchronous and asynchronous support (Brancaccio, et al., 2015b). The analysis of these different experimentations made it possible to detect some difficulties that are common among teachers. They all mainly related to the integration of technologies into didactic and to the time dedication that the training requires. The average age of Italian teachers is around 55, it is a challenge for them to change their practices and to learn how to use technological instruments; many of them are worried of not being good enough to manage similar activities in their classes. The key factors which allow them to overcome these difficulties, besides the help from the community, are their attitude and their openness to interactive learning. Learning must be a sharing practice, those who accept to learn from their students will get the highest results.

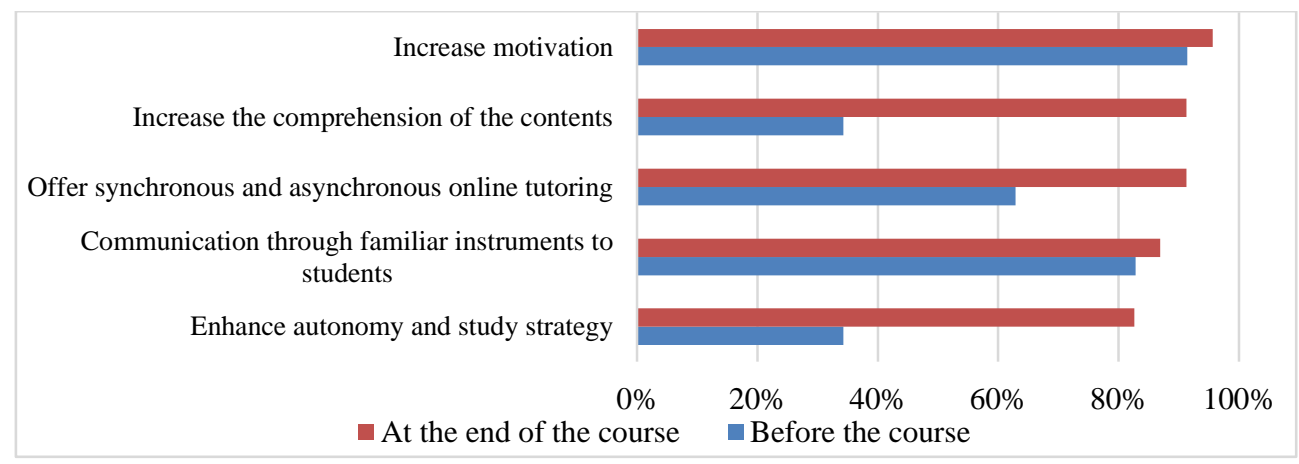

Figure 1. Teachers' perspective of effectiveness of the methodologies before and after the training.

\section{Conclusions}

In conclusion, the model for training teachers on the use of innovative digital methodologies for Mathematics, developed and experimented by the Department of Mathematics of the University of Turin, managed to give excellent results in terms of satisfaction and learning outcomes. Key strengths of this model are collaboration, sharing of practices and the presence of tutors. Creating and monitoring an online community of practice is a great endeavor for the University which dedicates time, money and employees in the maintenance of the platform and in the assistance to the training. However, good results show that it is worth the effort. In order to meet the teachers' need of certification of competences, some variations to the model are being experimented short cycles of synchronous tutoring replace the weekly ones; teachers must attend the web sessions and 
produce learning materials to get the certification of the achievement of methodological competences. Moreover, the Department is interested in extending the model to other subjects. A first experimentation with Latin has already been realized with the collaboration of the department of Human Studies, with much satisfaction of all participants.

\section{References}

Avalos, B. (2011). Teacher professional development in Teaching and Teacher Education over ten years. Teaching and Teacher Education, 27, 10-20.

Barana, A., \& Marchisio, M. (2016). Ten good reasons to adopt an automated formative assessment model for learning and teaching Mathematics and scientific disciplines. Procedia - Social and Behavioral Sciences. 228, 608-613. Valencia: Elsevier.

Barana, A., Brancaccio, A., Marchisio, M., \& Pardini, C. (2015). L'efficacia della metodologia del "problem posing and solving" con l'utilizzo delle TIC nella didattica della matematica e delle materie tecnico-scientifiche. Bricks, 5(3), 105-127.

Brancaccio, A., Demartini, C., Marchisio, M., Palumbo, C., Pardini, C., Patrucco, A., \& Zich, R. (2015a). Problem Posing and Solving: Strategic Italian Key Action to Enhance Teaching and Learning of Mathematics and Informatics in High School. Proceedings of COMPSAC Symposium on Computer Education and Learning Technologies (CELT).

Brancaccio, A., Marchisio, M., Meneghini, C., \& Pardini, C. (2015b). Matematica e Scienze più SMART per l'Insegnamento e l'Apprendimento. Didamatica. Genova.

Council of European Union (2009). Council conclusions of 12 May 2009 on a strategic framework for European cooperation in education and training, 2009/C119/02.

Darling-Hammond, L., \& Bransford, J. (2007). Preparing teachers for a changing world: What Teachers Should Learn and Be Able to Do. Jossey-Bass.

Ellerani, P. (2010). Il Web 2.0: contesto per l'apprendimento continuo di comunità professionali? In P. Ellerani, \& M. Parricchi, Ambienti per lo sviluppo professionale degli insegnanti (13-38). FrancoAngeli.

Lave, J. (1991). Situating Learning in Communities of Practice. In L. B. Resnick, J. M. Levine, \& S. D. Teasley, Perspectives on socially shared cognition (63-82). American Psychological Association.

Marchisio, M., Melgiovanni, R., \& Rabellino, S. (2013). La piattaforma Moodle al servizio del recupero scolastico nel Progetto "Scuola dei Compiti" della Città di Torino. Atti del MoodleMoot Italia.

MIUR. (2010). Schema di regolamento recante "Indicazioni nazionali riguardanti gli obiettivi specifici di apprendimento concernenti le attività e gliinsegnamenti compresi nei piani degli studi previsti per i percorsi liceali di cui all'articolo 10 , comma 3 , del decreto".

MIUR. (2015, luglio 13). Legge n. 107, Riforma del sistema nazionale di istruzione e formazione e delega per il riordino delle disposizioni legislative vigenti. 
Official Journal of the European Union. (2006). Recommendation of the European Parlament and of the Council of 18 December 2006 on key competences for lifelong learning.

Palumbo, C., \& Zich, R. (2012). Matematica ed informatica: costruire le basi di una nuova didattica. Bricks, 2(4), 10-19.

PISA. (2003). Literacy Skills for the World of Tomorrow. OECD/UNESCO.

Prensky, M. (2001). Digital Natives, Digital Immigrants. On the Horizon, 9(5).

Supovitz, J. (2002). Developing communities of instructional practice. Teachers College Record, 104(8), 1591-1626.

Vescio, V., Ross, D., \& Adams, A. (2008). A review of research on the impact of professional learning communities on teaching practice and student learning. Teaching and Teacher Education, 24, 80-91. 